\title{
Transflective multiplexing of holographic polymer dispersed liquid crystal using Si additives
}

\author{
K. R. Sun ${ }^{1}$, Y. S. Kang ${ }^{2}$, B. K. Kim ${ }^{1 *}$ \\ ${ }^{1}$ Department of Polymer Science and Engineering, Pusan National University, Busan 609-735, Korea \\ ${ }^{2}$ Department of Chemistry, Sogang University, Seoul 121-741, Korea
}

Received 29 June 2010; accepted in revised form 18 September 2010

\begin{abstract}
Morphology, grating formation dynamics and electro-optical performance of transflective multiplexing with holographic polymer dispersed liquid crystal (HPDLC) were investigated in the presence of silica nanoparticles (Aerosil R812 (RS) and modified Aerosil 200 (MS)) and silicon monomer (vinyltrimethoxy silane (VTMS)) by using three coherent laser beams. The addition of Si additive significantly augmented the diffraction efficiencies of transmission and reflection gratings due to the enhanced phase separation with large LC channels. The film was driven only with Si additives which are enriched at the polymer-LC interfaces. As the additive content increased, driving voltage decreased to a minimum of $30 \mathrm{~V}$ at $2.0 \mathrm{wt} \%$ VTMS. It was found that the interface modification and large droplet size are crucial to operate the film. Among the three types of Si additive, VTMS showed the highest electro-optical performance due to its low viscosity and high reactivity.
\end{abstract}

Keywords: nanocomposites, multiplexing, HPDLC, transflective grating, silica

\section{Introduction}

The development of an optimum recording material remains one of the principal challenges in the area of holographic data storage [1-3]. Holographic photopolymers, first reported in the late 1960s by Close et al. [4], are attractive candidates for applications in data storage [5-7] though they have limited memory capacity at this moment.

Holographic storage has long been the promise for large digital storage capacity because the information packing densities can be considerably increased by using three-dimensional storage techniques $[8$, 9]. Various kinds of recording configurations have been proposed for this purpose $[10,11]$. In general, these methods require an independent specific reference beam to interfere with the object beam to perform the recording.

${ }^{*}$ Corresponding author, e-mail: bkkim@pnu.edu

(c) BME-PT
Holographic storage also enables fast data transfer because it permits reading and writing of data simultaneously. There are a number of multiplexing schemes to store many holograms in the same volume such as angular [12-15], peristrophic $[16,17]$, shift multiplexing $[18,19]$ or by more than one of these techniques in combination [20-22], which are used to store multiple holograms at the same location. In these methods, angular multiplexing is probably the most common in which the reference beam is incident upon the sample at difference angle to record each hologram. However, earlier studies showed relatively low and non-uniform diffraction efficiency of each multiplexed hologram. In this paper, we propose a high and uniform efficiency holographic storage system with three coherent laser beams for transflective multiplexed 
HPDLC using angular multiplexing method. To obtain high and uniform diffraction efficiency, we incorporated various amounts of silica nanoparticles, virgin and chemically modified ones, and silicon monomer which have high refractive index and low free energy into the polymer matrix. These HPDLC films are also expected to lower the driving voltage and the response time in addition to the enhanced diffraction efficiency.

\section{Experimental}

\subsection{Materials}

The typical recipe for writing HPDLC gratings consists of multi-functional monomer (oligomers), reactive diluents, additives, and LC in the presence of suitable photoinitiator dye and coinitiator.

To synthesize urethane oligomers, a molar excess of hexane diisocyanate (HDI, Aldrich, St. Louis, America) $\left(\right.$ molecular weight $=168.20 \mathrm{~g} \cdot \mathrm{mol}^{-1}$ ) was reacted with bifunctional polypropylene glycol (PPG, Korea Polyols, Korea) $\left(M_{\mathrm{n}}=400 \mathrm{~g} \cdot \mathrm{mol}^{-1}\right)$ for over $1 \mathrm{~h}$ at $80^{\circ} \mathrm{C}$ to obtain NCO-termination. Then the reaction mixture was cooled down to $40^{\circ} \mathrm{C}$ and 2-hydroxylethyl acrylate (HEA, Aldrich, St. Louis, America) $\left(\right.$ molecular weight $\left.=116.12 \mathrm{~g} \cdot \mathrm{mol}^{-1}\right)$ was added to obtain HEA-capped urethane acrylate oligomer (called oligomer) having a molecular weight of $968.64 \mathrm{~g} \cdot \mathrm{mol}^{-1}$.

The oligomers are highly viscous and immiscible with LCs, which necessitates the use of reactive diluents. Two types of reactive diluents, viz. N-vinylpyrrollidinone (NVP, Aldrich, St. Louis, America) and dipentaerythritol penta-/hexa-acrylate (DPHPA, Aldrich, St. Louis, America) were used and the composition of oligomer/monofunctional/multifunctional diluents was $4: 3: 3$ by weight.

In addition, silica nanoparticles (Aerosil R812 (RS), Degussa, Canada, diameter $=7 \mathrm{~nm}$ ), vinyl modified Aerosil 200 (MS, Degussa, Canada, diameter $=12 \mathrm{~nm}$ ), and silicon monomer (vinyltri- methoxy silane (VTMS), Aldrich, St. Louis, America) (hereafter called Si additive) have been added to the mixture. VTMS is a liquid at ambient conditions and it reduces the mixture viscosity significantly. Silica nanoparticles and VTMS were obtained from Degussa and Aldrich respectively. The LC used in our experiment was E7 (BL001, Merck, Germany), an eutectic mixture of four cyanobiphenyl and cyanoterphenyl mixture with $T_{\mathrm{NI}}=50.5^{\circ} \mathrm{C}, \varepsilon=19.0$, and $\varepsilon_{\perp}=4.2$. Rose Bengal was used as photo-initiator for holographic recording with Ar-ion laser $(\lambda=514 \mathrm{~nm})$, where N-phenylgycine was added as co-initiator. The prepolymer/ LC composition was $65 / 35$. Basic formulations are shown in Table 1.

\subsection{Modification of silica particles}

Aerosil 200 were first dispersed in DMF, followed by mixing and reaction with allyl isocyanate for $24 \mathrm{~h}$ at $80^{\circ} \mathrm{C}$ to obtain the vinyl modified silica particles (Figure 1). Then the sample was filtered and washed with acetone.
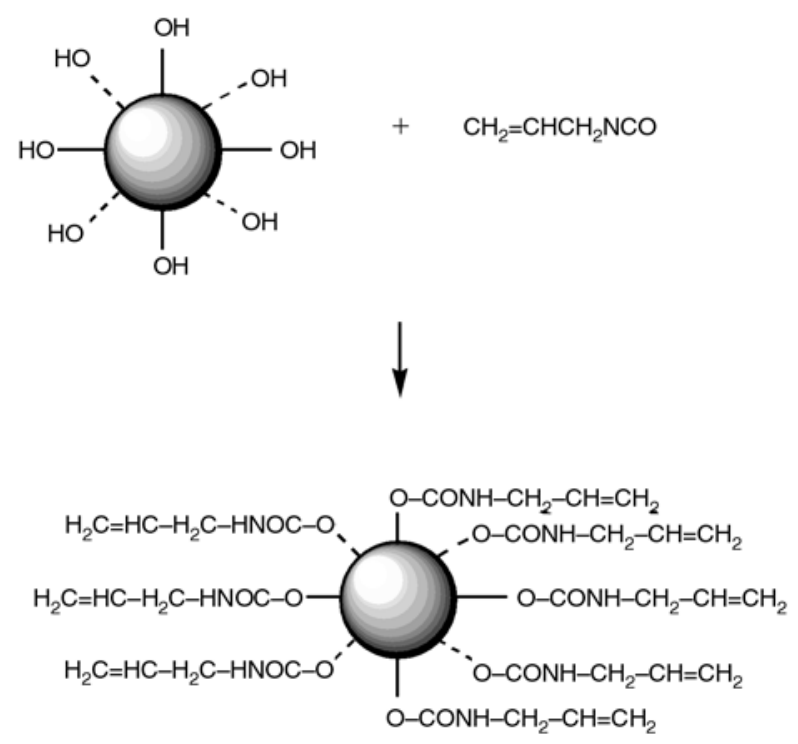

Figure 1. Reaction scheme to modify the Aerosil 200 with allyl isocyanate

Table 1. Formulations to fabricate HPDLC films

\begin{tabular}{|c|c|c|c|c|c|c|c|c|}
\hline \multicolumn{9}{|c|}{ Composition[wt\%] } \\
\hline Oligomer & \multicolumn{2}{|c|}{ Diluents } & \multicolumn{2}{|c|}{ Initiator } & \multicolumn{3}{|c|}{ Additive } & LC \\
\hline PPG400 HDI HEA & DPHPA & NVP & RB & NPG & RS & MS & VTMS & E7 \\
\hline \multicolumn{3}{|l|}{63.63} & \multirow{6}{*}{0.20} & \multirow{6}{*}{1.17} & None & None & None & \multirow{6}{*}{35} \\
\hline \multicolumn{3}{|l|}{63.37} & & & 0.26 & 0.26 & 0.26 & \\
\hline \multicolumn{3}{|l|}{63.11} & & & 0.52 & 0.52 & 0.52 & \\
\hline \multicolumn{3}{|l|}{62.85} & & & 0.78 & 0.78 & 0.78 & \\
\hline \multicolumn{3}{|l|}{62.59} & & & 1.04 & 1.04 & 1.04 & \\
\hline \multicolumn{3}{|l|}{\begin{tabular}{|l|}
62.33 \\
\end{tabular}} & & & 1.30 & 1.30 & 1.30 & \\
\hline \multicolumn{8}{|l|}{65.00} & 35 \\
\hline
\end{tabular}




\subsection{Grating preparation and measurements}

Figure 2 shows the multiplexed holographic recording system. An Ar-ion laser (514 nm) with a total power of $150 \mathrm{~mW} / \mathrm{cm}^{2}$ was used as light source. Relative intensities of the three beams were 10 (B2)/5 (B1, reference beam)/5 (B3). These three beams were reflected from the mirrors and then impinged on the cell from the same and the different side of the cell. The cell was constructed by sandwiching the oligomer/LC mixture between the two indium tin oxide (ITO) coated glass cells, with a gap of $10 \mu \mathrm{m}$, adjusted by a bead spacer. The interference of the three beams established the periodic interference pattern according to Bragg's law. The two intersections between the reference (B1) and object beams (B2, B3) were respectively set at $22^{\circ}$ and at $180^{\circ}$. Powder samples for infrared (PerkinElmer, New York, America) and H-NMR (Varian, New York, America) measurements were prepared after evaporating the solvent used for modification of silica particles.

The diffraction efficiencies of the holographic gratings were measured with a photo-diode using Arion laser. The transmitted beams and reflected beams were detected with a photodiode detector. Diffraction efficiency is defined as the ratio of diffraction intensity after plate divided by the transmitted beam intensity before plate. Real time grating formation was monitored using $\mathrm{He}-\mathrm{Ne}$ laser probe $(633 \mathrm{~nm})$ since the material is not sensitive to red light. UV-visible spectra of unfilled (virgin) and additive filled resins were determined using a UVvisible spectrophotometer (Mecasys Optizen, Korea) at ambient temperature. The baseline was drawn with blank cell of glass substrate.
For electrooptic measurements, a square wave voltage $(60 \mathrm{~Hz}$ sine wave pulse of $50 \mathrm{~ms})$ operating from 0 to $50 \mathrm{~V}$ was applied across the HPDLC cell. The drive signal and the response of the photodiode were monitored with a digital storage oscilloscope (Hitachi VC-6023, Japan). The response time is defined as the time taken to relax from 90 to $10 \%$ of the maximum switching difference under an electric field.

LC was extracted in methanol for $24 \mathrm{~h}$ before the morphology was examined under the scanning electron microscopy (SEM, Hitachi S430, Japan). Samples were fractured in liquid nitrogen and the fractured structures were scanned. The contact angle with an LC drop was measured on the surface of polymer cured with UV radiation for about $10 \mathrm{~min}$ with $0.1 \mathrm{wt} \%$ 1-hydroxy-2-methyl-1-phenylpropan1-one (Darocur1173, Ciba Specialty Chemicals, Switzerland) as an initiator using a contact angle meter (G-1, Erma).

\section{Results and discussion 3.1. FT-IR and ${ }^{1} \mathrm{H}-\mathrm{NMR}$}

The structure of vinyl modified silica (Figure 1) was confirmed by FT-IR and ${ }^{1} \mathrm{H}-\mathrm{NMR}$ measurements in Figure 3. The IR spectra of modified one show the characteristic peaks of the $\mathrm{NH}$ group $\left(3338 \mathrm{~cm}^{-1}\right), \mathrm{C}=\mathrm{C}$ group $\left(1628 \mathrm{~cm}^{-1}\right)$ and $\mathrm{CNH}$ group $\left(1580 \mathrm{~cm}^{-1}\right)$ which are formed by the urethane forming reactions (Figure 3a). In the ${ }^{1} \mathrm{H}-\mathrm{NMR}$ spectra (Figure 3b), signals from 5.89 to $5.83 \mathrm{ppm}$ are assigned to the protons of $\mathrm{CH}$ and $\mathrm{CH}_{2}$ (vinyl group), and those at 5.28 and $3.99 \mathrm{ppm}$ are assigned to the protons of $\mathrm{CH}_{2}$ and $\mathrm{NH}$. These

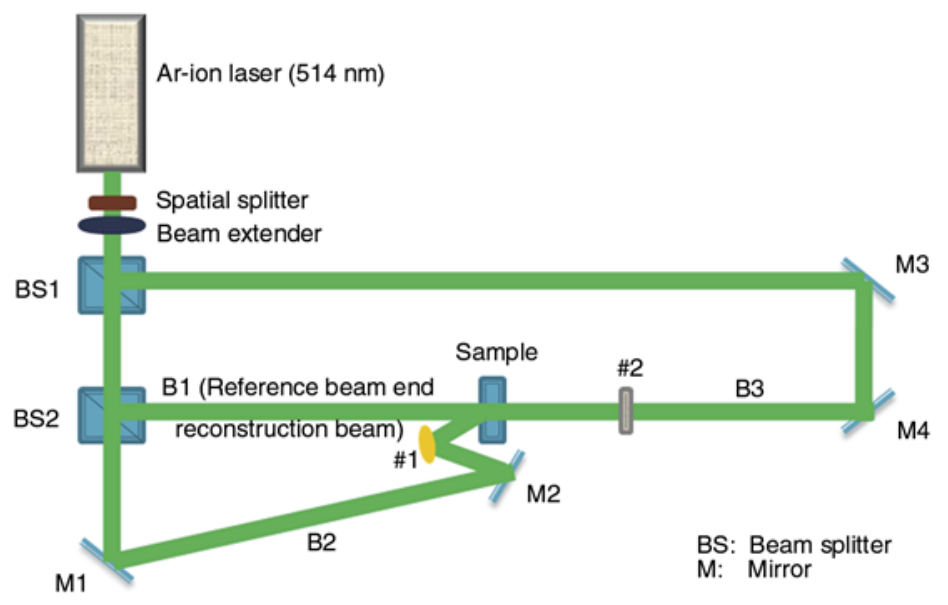

Figure 2. Optical set up for fabrication of transflective HPDLC films 

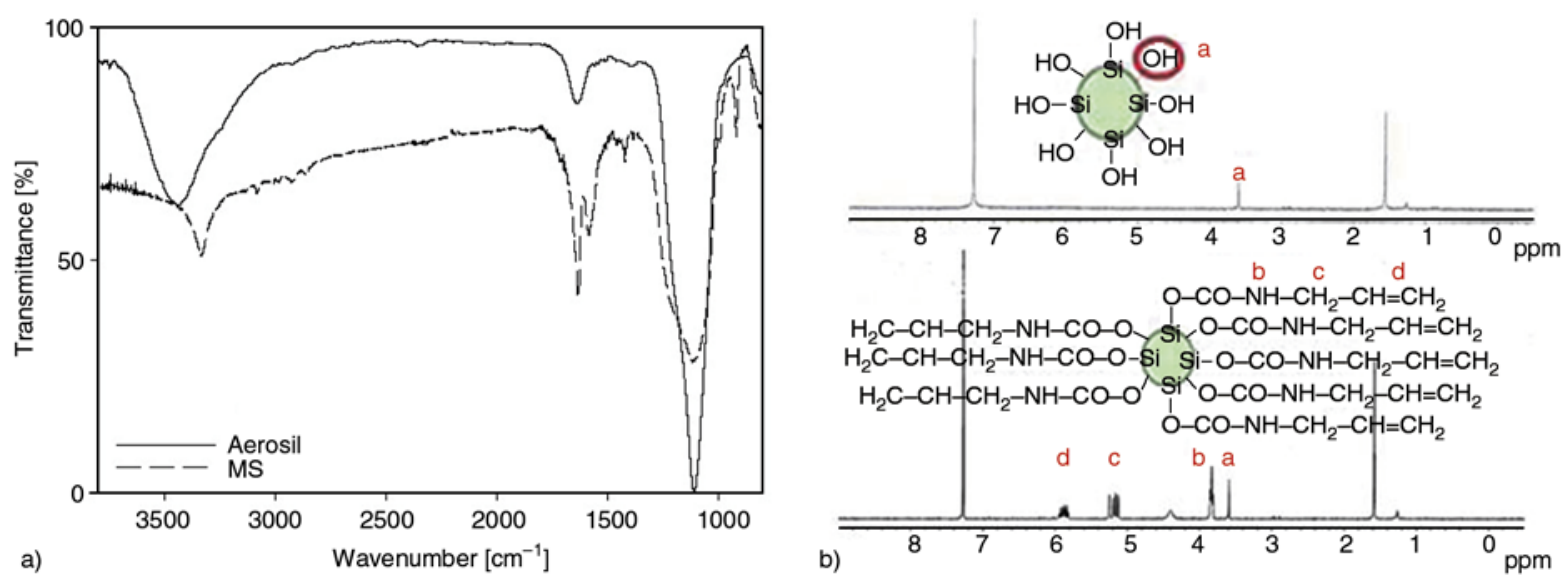

Figure 3. (a) FT-IR spectra and (b) ${ }^{1} \mathrm{H}-\mathrm{NMR}$ Spectrum of virgin Aerosil 200 particles and after reaction with allyl isocyanate

results confirm the incorporation of allyl isocyanate onto the silica surfaces.

\subsection{Contact angle}

The contact angle of the film with an LC drop increased monotonically with the addition and increasing amount of $\mathrm{Si}$ additive (Figure 4). This implies that the additives are preferentially migrated toward the surface due to the immiscibility and lower free energy of silicon atom. Notably, the effect was increasing along $\mathrm{RS}<\mathrm{MS}<\mathrm{VTMS}$, where



Figure 4. Contact angle of polyurethane acrylate film with an LC drop

a)

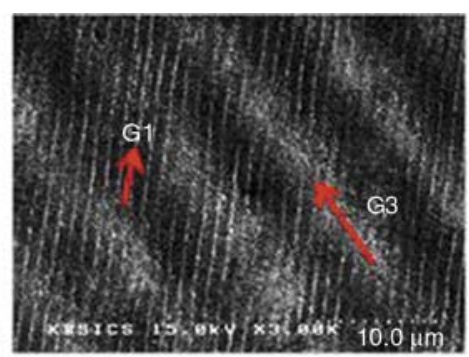

migration of VTMS was favored by its high diffusivity as liquid. An implication of the results is that silicon atoms are effectively exposed to the polymer-LC interfaces and reduce the anchoring energies of LC molecule on polymer surface along with reduced driving voltage as well [5].

\subsection{SEM morphology}

Typical multiplexed gratings at $3 \mathrm{~K}$ expansion are shown with $0.4 \mathrm{wt} \% \mathrm{MS}$ in Figure 5. One reference beam (B1) and two object beams (B2, B3) generated three gratings. Vertical transmission grating (G12) formed by B1 and B2, and slanted reflection grating (G13) formed by B1 and B3 are seen from the top view. A third reflection grating $(\mathrm{G} 23)$ formed by $\mathrm{B} 2$ and $\mathrm{B} 3$ is also seen from the edge view, where the edge is parallel to B1.

Figure 6, 7 and 8 respectively show the grating morphology at much high expansion (40K) for various contents of RS, MS and VTMS. Regardless of additive type, the width of LC channel increased with the addition and increasing amount of additive. The increase is presumably due to the increased resin phase elasticity which effectively squeezes the LC out of the resin phase to form a large LC chan-

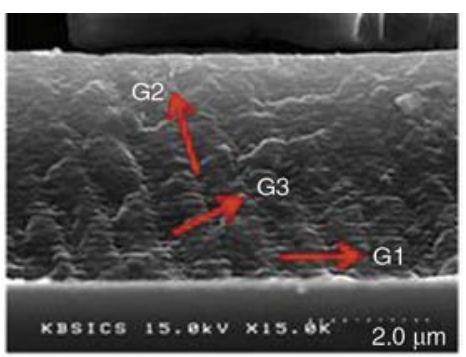

Figure 5. SEM micrographs of multiplexed gratings: (a) top view and (b) edge view 

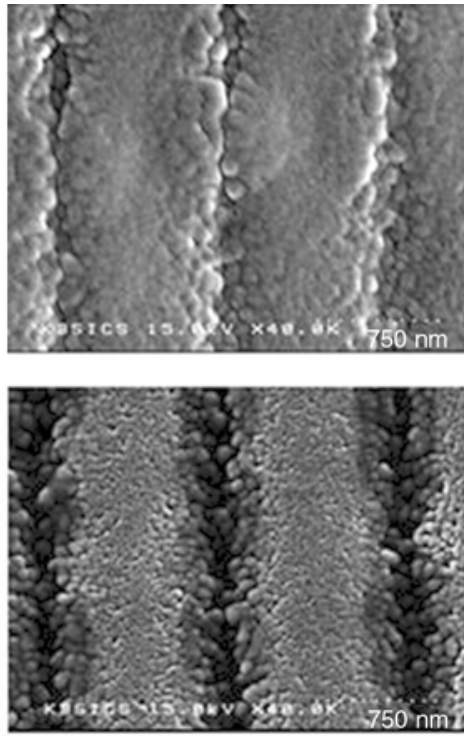

b)



d)

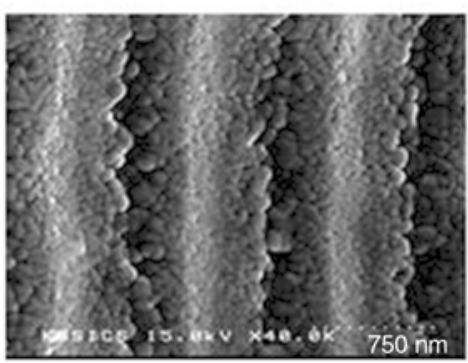

Figure 6. SEM micrographs of HPDLC films prepared (a) without, (b) with 0.4, (c) 1.2 and (d) 2.0 wt\% RS

a)

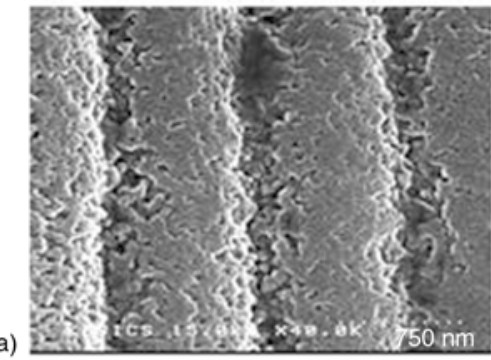

b)

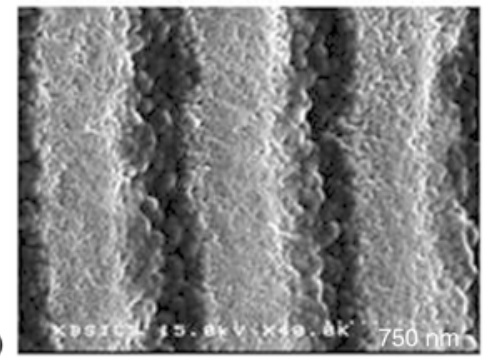

c)

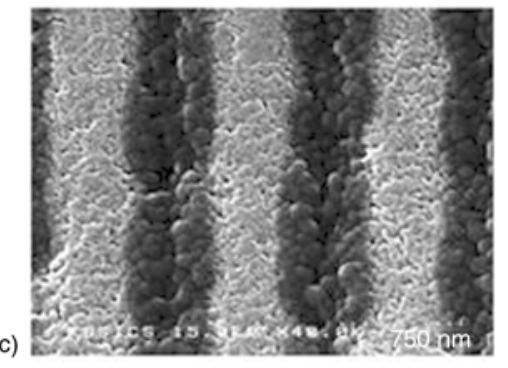

Figure 7. SEM micrographs of HPDLC films prepared (a) with 0.4, (b) 1.2 and (c) $2.0 \mathrm{wt} \% \mathrm{MS}$

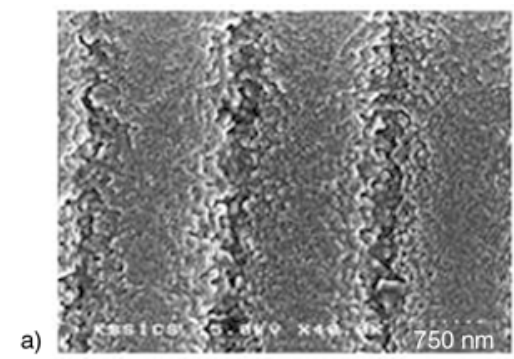

b)
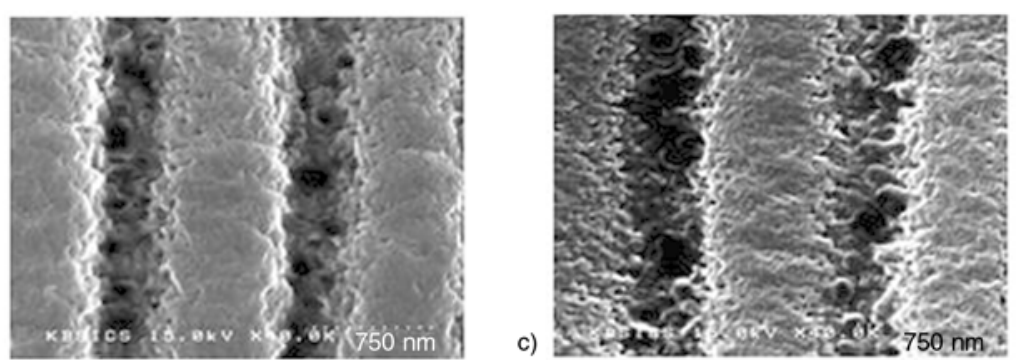

Figure 8. SEM micrographs of HPDLC films prepared (a) with 0.4 , (b) 1.2 and (c) $2.0 \mathrm{wt} \%$ VTMS

nel [7]. However, the effect is less pronounced with smaller particle (RS) since viscosity hinders diffusion. Increased phase separation should give high diffraction efficiency to follow. LC droplets which are not squeezed out of and remaining on the resin phase are larger for RS and smaller for MS. Resin surfaces are much smooth with VTMS due both to the homogeneous nature of resin phase and enhanced phase separation.

\subsection{Diffraction efficiency}

\subsubsection{Real-time diffraction efficiency}

With the addition and increasing amount of silica particles (RS, MS) nucleation and growth of peri- odic modulation are delayed followed by delayed saturation, more with RS and less with MS (Figure 9). This is due to the increased viscosity of the resin phase, which is greater with smaller particle (RS) [7]. Diffraction maximum is observed when the particle content is high. At this composition, elasticity driven phase separation is seemingly balanced with viscosity increase.

In contrast, VTMS induces nucleation faster than the virgin resin and gives much greater maximum and saturation diffraction than the RS and MS as well as virgin resin. It seems that the lower viscosity of VTMS inclusion drives fast diffusion, fast reaction, fast grating formation and phase separa- 

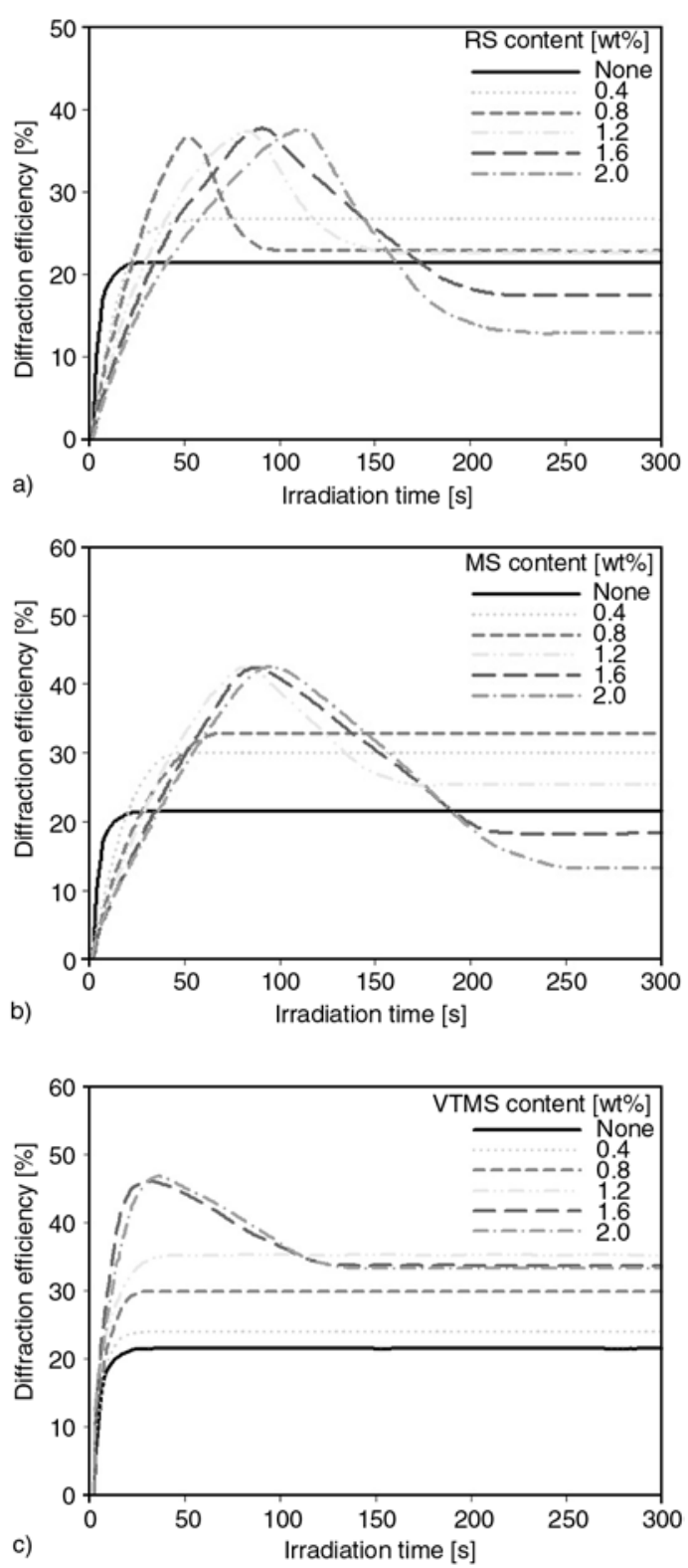

Figure 9. Real-time diffraction efficiency at various silica contents of HPDLC films prepared using (a) RS, (b) MS and (c) VTMS

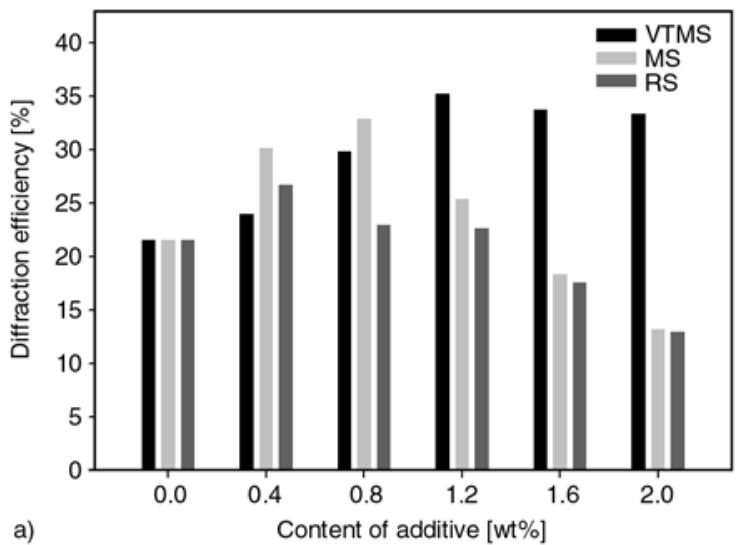

tion. Greater phase separation with VTMS was seen from the clean surface of resin phase (Figure 8 as compared with those of RS and MS (Figures 5 and 6).

\subsubsection{Diffraction efficiency}

Figure 10 shows diffraction efficiency of preferred gratings (G12, G13). As expected, diffraction efficiency of the multiplexed gratings is smaller than the conventional HPDLC system. This indicates that two different gratings which are simultaneously formed with three beams disturb the formation of the other [23]. However, it is mentioned that the two gratings give similar diffraction efficiencies of about 35 (G12) and 22\% (G13) though no exposure time scheduling has been used $[20,22]$.

Diffraction efficiency shows a maximum at 0.8 (RS, MS) or $1.2 \mathrm{wt} \%$ (VTMS) due to the enhanced phase separation [24]. For RS and MS the decrease after the maximum is due to the particle agglomeration [3]. The agglomeration is less with MS than with RS due to the chemical modification and incorporation of MS into the polymer matrix. For VTMS, extensive coalescence of LC droplets through less viscous matrix at higher silica contents led to high scattering loss giving small diffraction efficiency.

\subsection{Image recording and reconstruction}

Figure 11 show the original object patterns and their corresponding images as retrieved by reference beam. It is seen that the three retrieved images are fairly clear. The coin image (\#1 in Figure 2) was recorded by transmission grating using $\mathrm{B} 1$ and $\mathrm{B} 2$, whereas mosaic pattern (\#2 in Figure 2) by reflection grating using $\mathrm{B} 1$ and $\mathrm{B} 3$.

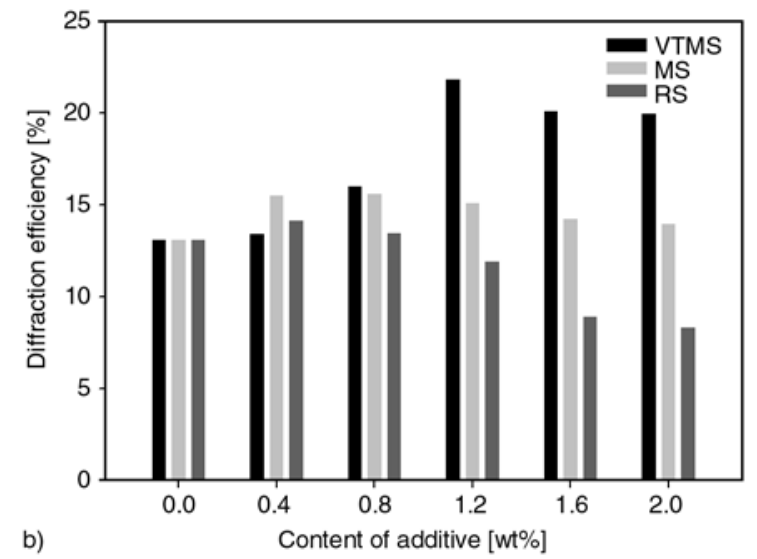

Figure 10. (a) Diffraction efficiency (R1) and (b) reflection efficiency (R2) vs. additive type and content of the holographic gratings 




a)

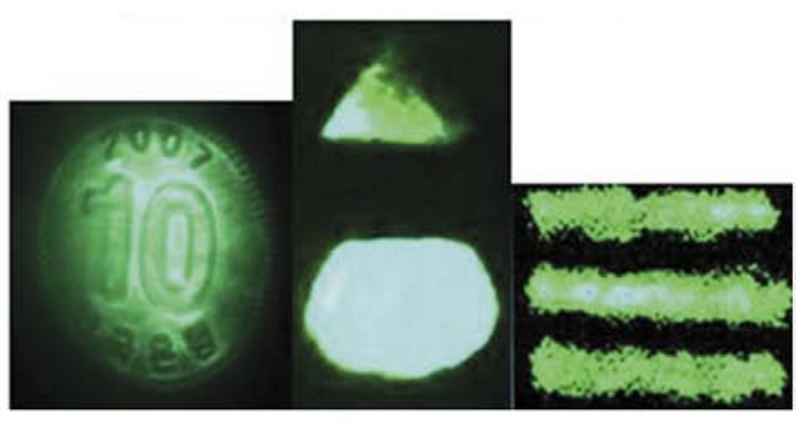

b)

Figure 11. Original object patterns (the top row) multiplexed in different angles, and their corresponding retrieved images (the bottom row)

\subsection{Electrical properties \\ 3.6.1. Driving voltage}

Figure 12 shows the driving voltage of HPDLC films. The virgin HPDLC film with no silica was not driven due to the strong anchoring strength between the polymer and LC [5]. It is seen that the film was driven only with silica particles and the switching voltage decreased with increasing amount of silica, where the lowest driving voltage of about $30 \mathrm{~V}$ was obtained at $2.0 \mathrm{wt} \%$ VTMS.

The presence of silicon atoms at the polymer-LC interfaces decreased interface energy to lower the surface anchoring and influenced the orientation of LC droplet directors. Regarding the effect of additive type, driving voltage decreased along the order of $\mathrm{RS}>\mathrm{MS}>$ VTMS.

Due to the photo-reactivity of VTMS and MS, these groups are incorporated into the chain end of polymer, and are preferentially exposed to the polymerLC interfaces. Among the two, VTMS having high reactivity and low viscosity is expected to be enriched more at the interfaces to give a dramatically decreased driving voltage.

\subsubsection{Response time}

Typical temporal response of a HPDLC film was measured at a particular composition of $0.8 \mathrm{wt} \%$ (Figure 13). Rise time was small $(0.28-0.34 \mathrm{~ms})$ while the decay time decreased along RS (1.92)> MS (1.82)>VTMS (1.28 ms). The additives which are interposed at the polymer-LC interfaces not only decrease the surface anchoring but also influence the orientation of LC droplet directions [25]. It seems that VTMS is a preferred interface modifier among the three.

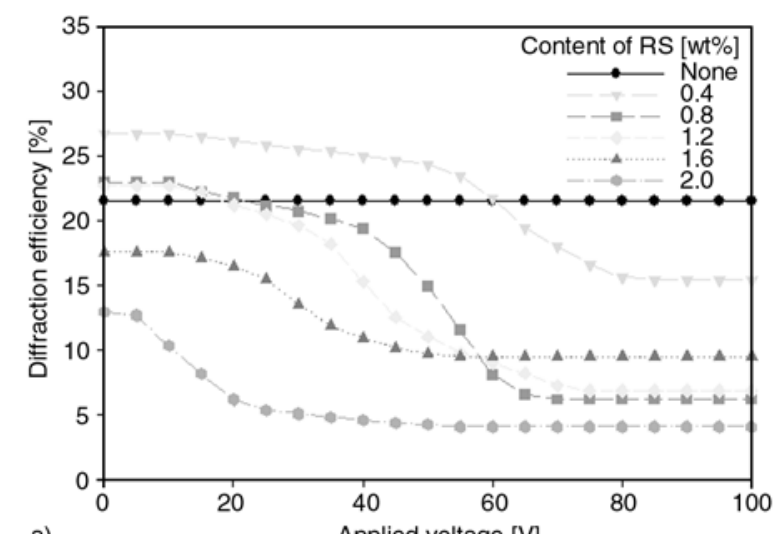

a)


Figure 12. Diffraction efficiency versus applied voltage at various silica contents of HPDLC films prepared using (a) RS, (b) MS and (c) VTMS 




Figure 13. Temporal response of the films as a function of the silica types (at $0.8 \mathrm{wt} \%$ additive)

\section{Conclusions}

Silica nanoparticles and silicon monomer have been introduced into the conventional formulation to fabricate angular multiplexed holographic polymer dispersed liquid crystal (HPDLC) and the effects have been studied in terms of grating formulation dynamics, morphology, diffraction efficiency, and electro-optical properties of the films.

The addition of Si additives significantly augmented the diffraction efficiencies of transmission and reflection gratings of the HPDLC. This was attributed to the enhanced phase separation with a large LC channel.

The film was driven only with $\mathrm{Si}$ additives which are enriched at the polymer-LC interfaces by the low free energy of silicon containing compounds to decrease the anchoring strength of LC molecule on polymer wall. As the additive content increased, driving voltage decreased to a minimum of $30 \mathrm{~V}$ at $2.0 \mathrm{wt} \%$ VTMS. It was concluded that the polymerLC interface modification and large droplet size are crucial to operate the film.

Regarding the effect of additive type, the highest electro-optical performances such as diffraction efficiency, driving voltage and response time were obtained with VTMS due to its low viscosity and high reactivity with the polymer matrix.

\section{Acknowledgements}

The research has been supported by the NCRC and PNUIFAM JRC Programs both organized at PNU.

\section{References}

[1] Haw M.: Holographic data storage: The light fantastic. Nature, 422, 556-558 (2003).

DOI: $10.1038 / 422556 a$

[2] Zilker S. J.: Holographic data storage - The materials challenge. ChemPhysChem, 3, 333-334 (2002).

DOI: $10.1002 / 1439-7641(20020415) 3: 4<333:$ AIDCPHC333>3.0.CO;2-W

[3] Del Monte F., Martínez O., Rodrigo J. A., Calvo M. L., Cheben P.: A volume holographic sol-gel material with large enhancement of dynamic range by incorporation of high refractive index species. Advanced Materials, 18, 2014-2017 (2006). DOI: $10.1002 /$ adma.200502675

[4] Close D. H., Jacobson A. D., Margerum J. D., Brault R. G., McClung F. J.: Hologram recording on photopolymer materials. Applied Physics Letters, 14, 159/1-159/2 (1969).

DOI: $10.1063 / 1.1652756$

[5] Woo J. Y., Kim E. H., Kim B. K.: Transmission holographic polymer dispersed liquid crystals based on a siloxane polymer. ChemPhysChem, 9, 141-146 (2008). DOI: $10.1002 /$ cphc. 200700521

[6] Poque R. T., Natarajan L. V., Siwecki S. A., Tondiglia V. P., Sutherland R. L., Bunning T. J.: Monomer functionality effects in the anisotropic phase separation of liquid crystals. Polymer, 41, 733-741 (2000).

DOI: 10.1016/S0032-3861(99)00196-2

[7] Kim E. H., Woo J. Y., Kim B. K.: Nanosized-silicareinforced holographic polymer-dispersed liquid crystals. Macromolecular Rapid Communications, 27, 553-557 (2006).

DOI: $10.1002 /$ marc. 200500784

[8] Das B., Joseph J., Singh K.: Phase modulated grayscale data pages for digital holographic data storage. Optics Communications, 282, 2147-2154 (2009).

DOI: 10.1016/j.optcom.2009.02.048

[9] Gu C., Xu Y., Liu Y., Pan J. J., Zhou F., He H.: Applications of photorefractive materials in information storage, processing and communication. Optical Materials, 23, 219-227 (2003). DOI: 10.1016/S0925-3467(02)00293-8

[10] Shahar R., Weiner S.: Insights into whole bone and tooth function using optical metrology. Journal of Materials Science, 42, 8919-8933 (2007).

DOI: $10.1007 / \mathrm{s} 10853-007-1693-8$

[11] Jeong E. H., Sun K. R., Kang M. C., Jeong H. M., Kim B. K.: Memory effect of polymer dispersed liquid crystal by hybridization with nanoclay. Express Polymer Letters, 4, 39-46 (2010). DOI: $10.3144 /$ expresspolymlett.2010.7

[12] Yau H-F., Liu J-P.: Angle multiplexed storage with object beam alone. Applied Physics Letters, 90, 181916/1-181916/3 (2007).

DOI: $10.1063 / 1.2733629$ 
[13] Ortuño M., Gallego S., García C., Neipp C., Beléndez A., Pascual I.: Optimization of a $1 \mathrm{~mm}$ thick PVA/ acrylamide recording material to obtain holographic memories: Method of preparation and holographic properties. Applied Physics B, 76, 851-857 (2003). DOI: 10.1007/s00340-003-1229-0

[14] Sherif H., Naydenova I., Martin S., McGinn C.: Characterization of an acrylamide-based photopolymer for data storage utilizing holographic angular multiplexing. Journal of Optics B, 7, 255-260 (2005).

DOI: $10.1088 / 1464-4258 / 7 / 5 / 007$

[15] El Hafidi I., Grzymala R., Kiefer R., Elouad L., Meyrueis P.: Optical data storage on protein using angular multiplexing. Optics and Laser Technology, 37, 503-508 (2005).

DOI: $10.1016 /$ j.optlastec.2004.06.008

[16] Mok F. H., Tackitt M. C., Stoll H. M.: Storage of 500 high-resolution holograms in a $\mathrm{LiNbO}_{3}$ crystal. Optics Letters, 16, 605-607 (1991).

DOI: 10.1364/OL.16.000605

[17] Curtis K., Pu A., Psaltis D.: Method for holographic storage using peristrophic multiplexing. Optics Letters, 19, 993-994 (1994). DOI: 10.1364/OL.19.000993

[18] Pu A., Curtis K., Psaltis D.: Exposure schedule for multiplexing holograms in photopolymer films. Optical Engineering, 35, 2824-2829 (1996).

DOI: $10.1117 / 1.600967$

[19] Steckman G. J., Pu A., Psaltis D.: Storage density of shift-multiplexed holographic memory. Applied Optics, 40, 3387-3394 (2001).

DOI: $10.1364 / \mathrm{AO} .40 .003387$
[20] Rakuljic G. A., Levya V., Yariv A.: Optical data storage by using orthogonal wavelength-multiplexed volume holograms. Optics Letters, 17, 1471-1473 (1992). DOI: 10.1364/OL.17.001471

[21] Fernández E., García C., Pascual I., Ortuño M., Gallego S., Beléndez A.: Optimization of a thick polyvinyl alcohol-acrylamide photopolymer for data storage using a combination of angular and peristrophic holographic multiplexing. Applied Optics, 45, 7661-7666 (2006).

DOI: 10.1364/AO.45.007661

[22] Sheridan J. T., O’Neill F. T., Kelly J. V.: Holographic data storage: Optimized scheduling using the nonlocal polymerization-driven diffusion model. Journal of the Optical Society of America B, 21, 1443-1451 (2004). DOI: 10.1364/JOSAB.21.001443

[23] Gallego S., Neipp C., Ortuño M., Fernández E., Beléndez A., Pascual I.: Analysis of multiplexed holograms stored in a thick PVA/AA photopolymer. Optics Communications, 281, 1480-1485 (2008).

DOI: $10.1016 /$ j.optcom.2007.11.068

[24] Bowely C. C., Fontecchio A. K., Crawford G. P.: Multiple gratings simultaneously formed in holographic polymer-dispersed liquid-crystal displays. Applied Physics Letters, 76, 523/1-523/3 (2000). DOI: $10.1063 / 1.125836$

[25] Fernández E., Ortuño M., Gallego S., García C., Beléndez A., Pascual I.: Comparison of peristrophic multiplexing and a combination of angular and peristrophic holographic multiplexing in a thick PVA/ acrylamide photopolymer for data storage. Applied Optics, 46, 5368-5373 (2007). DOI: 10.1364/AO.46.005368 